\title{
A Method for Data-mining of Defects on Building Façade Elements
}

\author{
Jaeseob Lee ${ }^{1}$, Yongdeok Jeon ${ }^{1}$, Kichang Jeong ${ }^{2}$, Yeonwoo Shin ${ }^{1}$, Wooram Kim ${ }^{1}$ \\ ${ }^{1}$ Department of Architectural Engineering, Dongguk University, Korea \\ ${ }^{2}$ Construction Cost Management Research Institute, Korea \\ js1998@dongguk.edu, claimjeon@naver.com,therza@hanmail.net, \\ yeonwoo124@hotmail.com,seraphs4u@naver.com
}

\begin{abstract}
It has been recognized that the value of buildings gradually decreases over time due to aesthetic, functional, and structural deteriorations caused by various defects.In response to these deteriorations, the value of buildings can be restored by various types of maintenance operations. However, minimizing depreciation is better than mantenance. In this regard, the defects that cause depreciation should be reduced through data analysis on existing buildings. This study suggests the "Pixelization Method (PM)" for data mining on building façade elements to collect data on facade defects. PM is a technique that supports the creation of a database by simplifying the analysis of building façades as well as the input data. The database, developed with PM, is expected to be used in various areas such as analysis of the relationshtp between the defects and the facade elements or the prediction of defect
\end{abstract}

Keywords: Pixelization Method, Defects, Faşade, Database

\section{Introduction}

Buildings are made and ulsed for a ong time to provide housing and living space. In this aspect, severat buildings have enough significance to serve as symbols in cities. Therefore, buildings have value and are not merely structures. However, over time, defects that cause the degradation of aesthetics, functionality, and structure are common, so the value of buildings deceases gradually. In this regard, a way to minimize or prevent defects is essential.

Identifying the faetors that affect defects and analyzing the relationship between the factors and the defects is clearly needed. The factors can be classified as environmental factors, site conditions, building characteristics, materials, and building façade elements. Data on factors can be easily collected from land books, weather information, map, etc., but selecting a method for determining information on façade elements is not clear. The reason is that there are so many kinds of façade elements, and various sizes and shapes for each element. Additionally, these elements are complex and the collection of data takes a lot of time and effort. Considering that the object of analysis is existing building façades, a simple, easy and accurate method for data-mining is needed.

This study suggests the 'Pixelization Method (PM)' for data mining. PM is a method for mining data by dividing building façades into typical compartments and inputting the characteristics of each compartment. Therefore, PM collects data from the perspective of the entire building façade in contrast with the individual approaches of existing studies. This paper proceeds as follows.

First, this paper analyzes previous studies on defects and the types of countermeasures employed to determine the need for PM for the purpose of establishing a base for the study. Second, the concepts and processes of data collection for PM are described. Finally, the paper presents the potential of PM with an example involving the collected 
data. Typically, previous studies targeted defects in the construction phase, but this paper focuses on defects in the use phase, which actually result in significant depreciation.

\section{Methodology}

\subsection{Defects in Building Exterior Wall}

Defects in the building façade are the main factors that cause depreciation. In this regard, Brimblecombe and Grossi (2005) analyzed building exteriors as well as the color and pollution of stone, while Lourenço, et al. (2006) identified the relationship between defects based on the building shape and the material, indoor temperature and humidity. Hong (2011) suggested the use of a management plan and recognition of the main content for defect prevention during the construction phase. Silva, et al. (2011) predicted the average lifespan of buildings using a life prediction model with stone finishes. Neto and Brito (2012) analyzed the relationship between each factor related to stone defects. Hebert, et al. (2012) examined the causes of defects in and outside buildings. In addition, various depth studies have been conducted on defects. However, analysis of defects limited to the specific conditions is less practical because related factors act in combination to cause or increase the defect. Also, analysis of defects in the use phase alone is not sufficient becatse of limitations of the study scope. Therefore, a case study and extension of the range of defects is needed for actual occurrence analysis and development of a management plan.

\subsection{Influencing Factors of Defect}

There are several factors that causedefects and these factors interact in a complex manner. The factors are classified in Table 1.

\section{Table 1. Influential Eactors for Defects}

\begin{tabular}{|l|l|}
\hline Division & Remarks \\
\hline Year & Relation type (Straight, Accelerated, Gentle, Moment) \\
\hline Site Condition & Zone, Altitude, Distance from the Coast, Road Width, etc. \\
\hline Material & Type, Shape Size, Surface, Joint, Color, etc. \\
\hline Building & Area, Height, Stories, Structure, Roof type, etc. \\
\hline Façade Element & Aspect, Accessibility, Slope, Peak, Dent, Open, Fixture, etc. \\
\hline
\end{tabular}

\subsection{Defect Analysis Methód}

Failure Mode and Effect Analysis (FMEA)' is a step-by-step approach for identifying all possible failures in a design, manufacturing or assembly process, as well as in a product or service. When applied to a defect, the key management factor is selected by evaluating the characteristics of the defect over the life-cycle. For this purpose, the quantification of defect data is necessary, but is difficult to perform using traditional methods. Therefore, a new method for creating a database for defects over the life-cycle is needed.

\subsection{Summary}

Previous studies on defects focused on the analysis of individual characteristics and were limited to the construction phase. Consequently, information on defects in the use phase is insufficient. Defects that occur in the use phase can be managed by FMEA or other methods, but data collection is limited. So, this study proposes the 'Pixelization Method (PM)' for data collection about defects in building façades and façade elements. 


\section{3. "Pixelization Method" for Mining Exterior Wall Information}

\subsection{Definition}

The 'Pixelization Method (PM)' is a data collection method that separates the building façade into compartments. In PM, data is inputted based on the characteristics of each compartment. It uses the concept of color analysis employed in the Korea Standard Color Analysis and aims for easy data collection by simplifying the building façade. The concept of PM is as follows (Figure 1.).

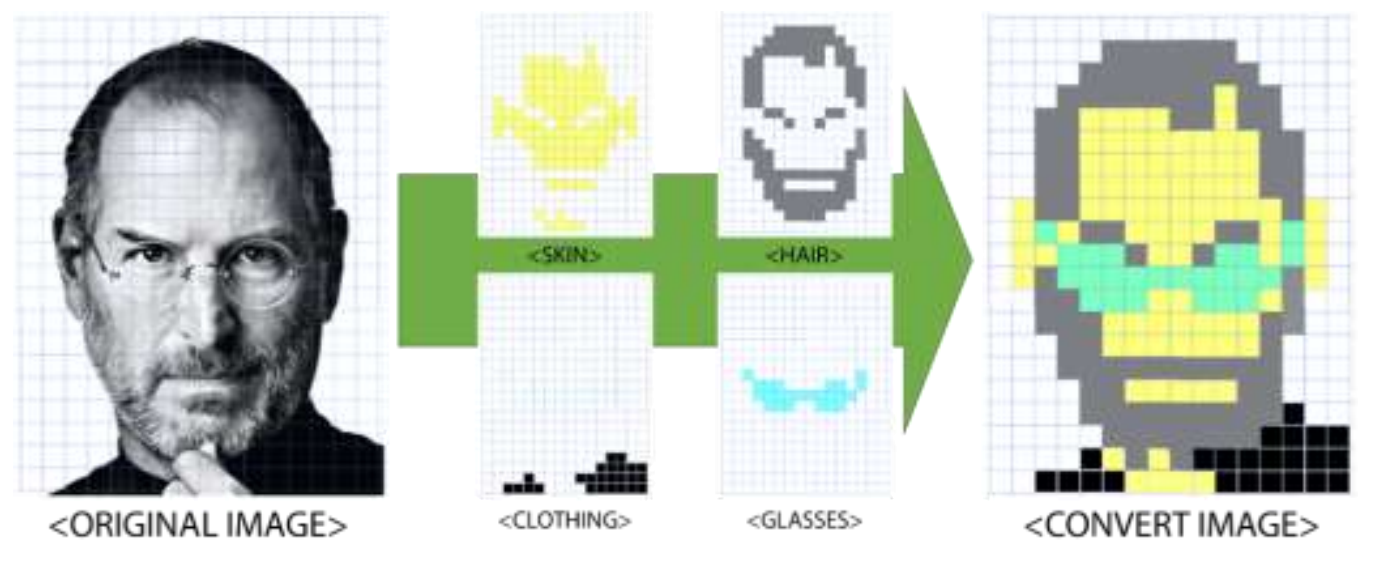

Figure 1. Concept of Pixelization Method

Suppose information about the skin, hair, chothing and glasses are obtained from a human face. First, a grid line is drawn above the image of the human face (<ORIGINAL IMAGE> in Figure 1.) and a compartment unit is created. Then, the data is checked based on the presence or absence of each factor in the compartment unit. Finally, the data is combed to create the final database (<CONVERT IMAGE $>$ in Figure 1.).

Comparing <ORIGANAL IMAGE> and <CONVERT IMAGE>, the overall characteristics can be observed, but some detailed information is missing. This is a weak point of $\mathrm{PM}$, but considering the data mining process and the characteristics of the information, the range is acceptable and can be complemented with additional study.

\subsection{Data Collection Process for "Pixelization Method"}

PM consists of a process that separates a building image into compartments, inputs codes for the characteristics in each matrix and converts each matrix to the database matrix. The detailed process is as follows (Figure 2.):
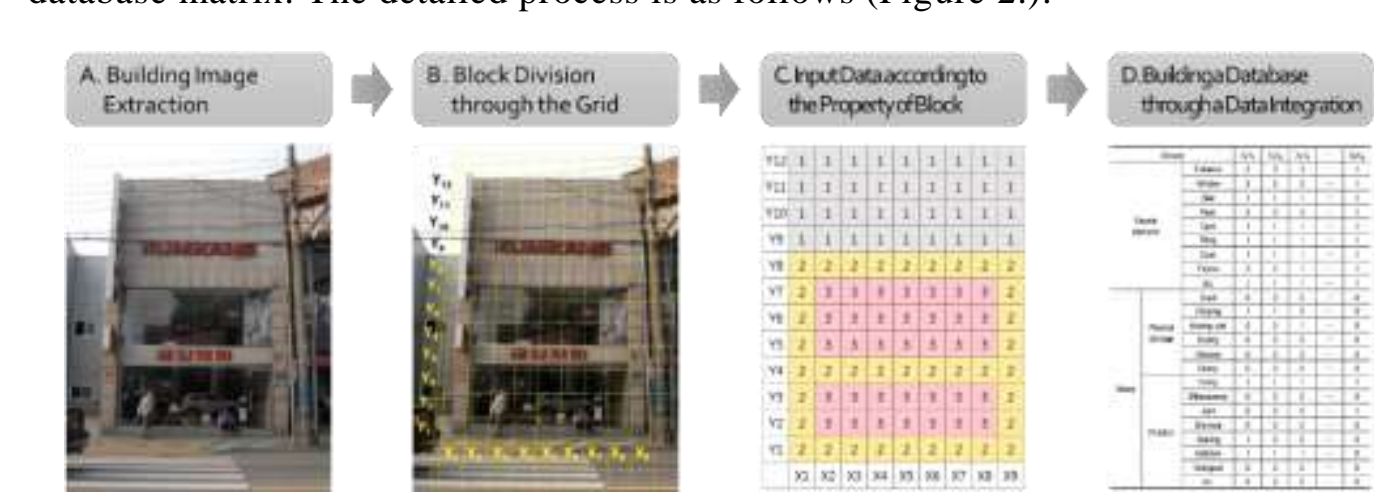

Figure 2. Process of Pixelization Method (J.S. Lee, 2016) 


\section{(1) Building Image Extraction}

To divide a building façade into compartments, the image of the building façade must be collected first. The actual appearance is required, so pictures should be obtained from the front of the building. To minimize the distortion according to the viewpoint, the façade is fit within one frame in the image. Therefore, there is a limit on target building size, but this limit can be complemented through additional study (Figure 3.). Figure 2A. shows an example of image data. The compartments are separated and data collection based on the compartments is performed in the next step.

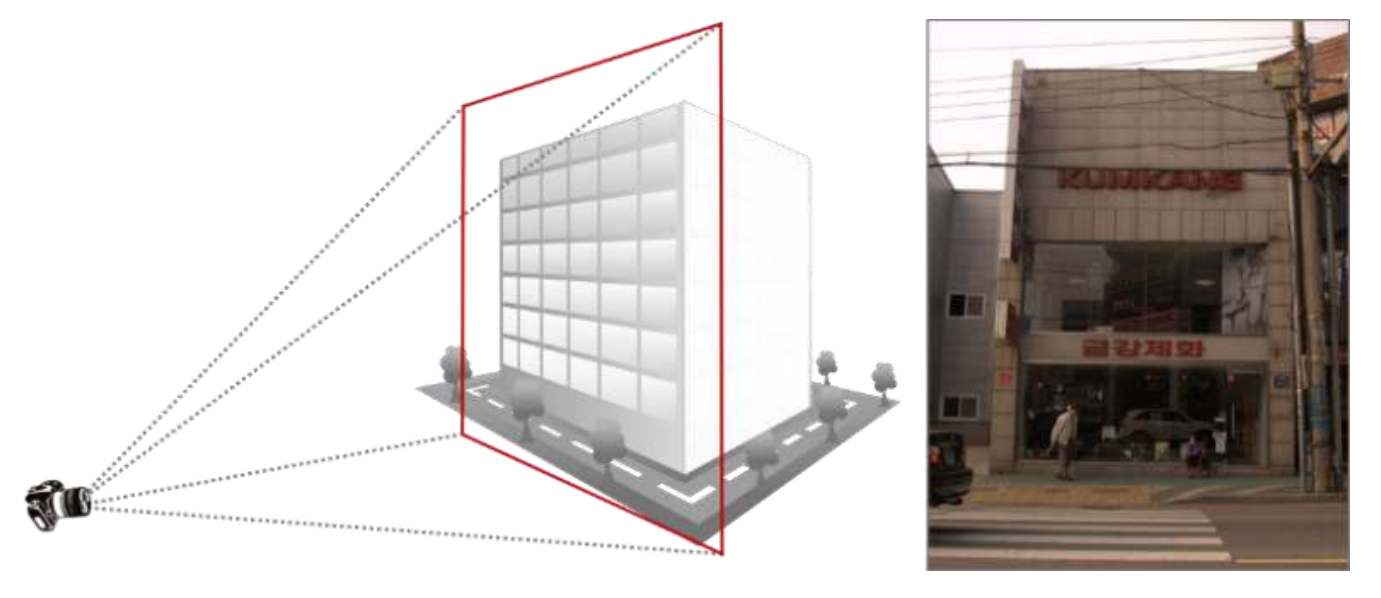

Figure 3. Building Image Extraction

(2) Block Division through the Grid

The image obtained in the first \$tepis divided into compartments. The compartment size is $1 \times 1(\mathrm{~m})$ and the number of compartments $(\mathrm{H} \times \mathrm{W})$ varies depending on the height $(\mathrm{H})$ and width (W) of the building. In consideration of possible distortion due to the linear perspective, this study uses the 'vanishing,point' in Photoshop@ to draw the interval lines. Based on the grid, codes are as signed to each unit (Figure 4.). Figure 2. B shows an example of the grid in the image. In this case, the building was divided into 108 compartments (H: 12, W: 9).

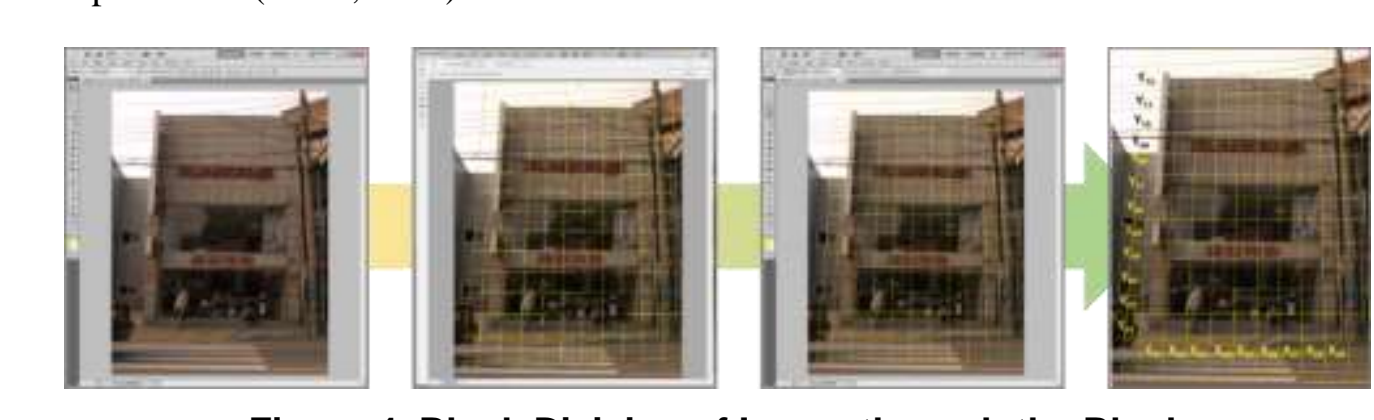

Figure 4. Block Division of Image through the Block

(3) Input Data according to the Block Property

Data is inputted based on the characteristics of the compartments in the image. Prior to input, entry factors should be set in advance according to the factors to be analyzed or collected. Each factor should be capable of being visually separated into façade elements or defects (Table 2). Each factor has a $\mathrm{H} \times \mathrm{W}$ matrix, and codes are inputted in the presence or absence of factors (Figure 5.). In Figure 5. B, X2Y2 to $\mathrm{X} 8 \mathrm{Y} 3$ and $\mathrm{X} 2 \mathrm{Y} 5$ to $\mathrm{X} 8 \mathrm{Y} 7$ are windows, so code 3 is inputted for windows and code 
2 is used for an adjacent area (Figure 2. C). Codes for other factors are inputted similarly

Table 2. Block Input Division Example

\begin{tabular}{|l|l|l|}
\hline Division & Sub Division & Code \\
\hline $\begin{array}{l}\text { Façade } \\
\text { Elements }\end{array}$ & X, Y, Entrance, Window, Stair, Peak, Dent, Tilting, & $\begin{array}{l}\text { Absence: 1, Adjacent: } \\
\text { 2, Presence: 3 }\end{array}$ \\
\hline $\begin{array}{l}\text { Defect } \\
\text { Factors }\end{array}$ & $\begin{array}{l}\text { Crack, Chixture, Etc. } \\
\text { Glossy, Soiling, Efflorescence, Joint, Chemical, } \\
\text { Staining, Moisture, Biological, etc. }\end{array}$ & Matrix (area and amount) \\
\end{tabular}

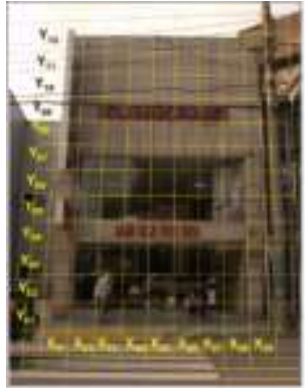

Input The Number in Each Axis

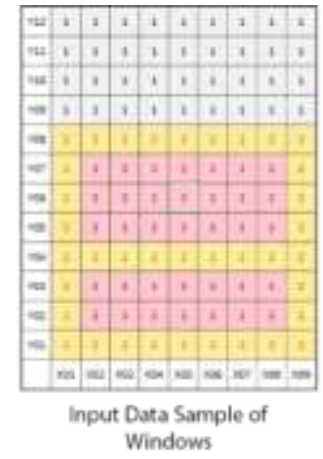

Windows

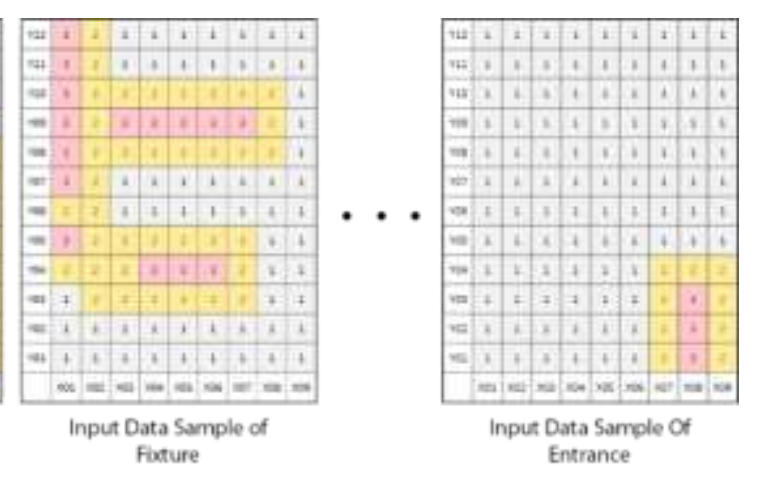

Entrance

Figure 5. Input Data According to the Block Property

(4) Building a Database through Data Integration

The matrix is formed by a number of factors (n), and the data for each matrix is converted into one matrix. In other words, $n$ matrixes $(\mathrm{H} \times \mathrm{W})$ are converted into one matrix $(\mathrm{k} \times \mathrm{n}, \mathrm{k}=\mathrm{H} \times \mathrm{W})$. The final matrix is used for the database of the building façade elements or defects (Figure 6.). Figure 2. D shows the results of converting 9 façade elements and 14defects into one matrix. So, a total of 23 matrixes was converted into 1 matrix.

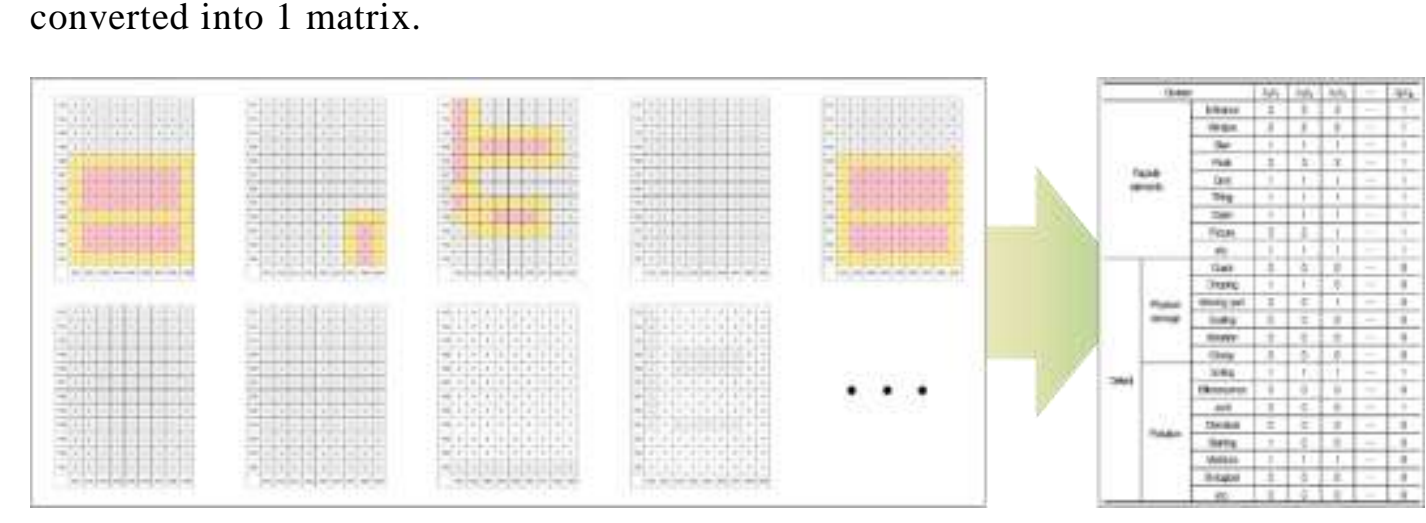

Figure 6. Building a Database through Data Integration

\subsection{Props and Cons of "Pixelization Method"}

PM is made for 'defect prevention through efficient design', abbreviated as 'DPTED' in this study, and thus involves easy data collection. A database is created by inputting data for the characteristics of compartments in the building façade based on Excel@. Therefore, it has the advantage of reflecting the characteristics of the building as well as easy data entry. This is clearly reflected in the defect analysis mentioned earlier. 
However, there are some limitations. First, data input is manual and can take a lot of time despite the low difficulty level. Also, in the event of unusual or oversized shapes, it is difficult to apply the method because of limitations in image acquisition. However, PM is still in the early stages of development and is continuously being improved. Subsequent research will complement and increase the practicality of PM.

\section{Utilization of "Pixelization Method"}

This study proposes two applications based on the data obtained from PM. First, PM can be utilized to analyze the relationship between a façade and defects. Therefore, it can be employed to build a foundation for reviewing risks in the design phase and correlating façade elements with defects. Second, the method can be adopted for predicting the potential value deterioration by employing case-based reasoning in accordance with defect cases in an existing building. Thus, the application of the study is as follows.

\subsection{Relation Analysis of Façade Elements and Defects}

Relation analysis of façade elements and defects examines the correlation between façade elements by extracting properties from a section where defects occurred. An example can be an analysis of the characteristics of defects generated in regard to the horizontal and vertical position of the structure (Figure 7.). As shown in Figure 7., <Chipping> occurred in the lower evels of the building, while <Soiling> and <Joint> occurred in the upper part of the building and <Rust> occurred on the side at a high fregtency. It is as umed that the defects occurred according to the possibility of physical contact contact with rainwater and the position of attachment.
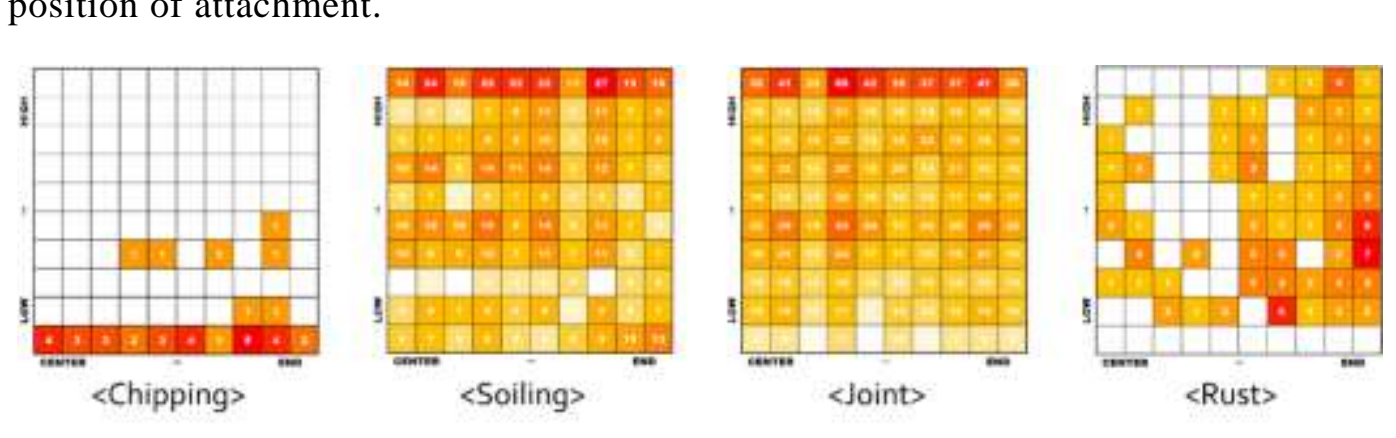

Figure 7. Distribution of Defect Occurrence in Facade

Aside from that, the relationship can be analyzed with various methods such as correlation and regression analysis. On the basis of these analyses, a standard for priofity control or precautions can be suggested.

\subsection{Predicting the Degree of Defects based on Case-based Reasoning}

Anticipation of the degree of defects in a building requires estimation by integration after deducting the degree of defects in similar cases based on building properties, distribution of defects according to building elevation and geographical conditions or use. The degree of defects in an existing building is determined by combining each factor that influences defects in buildings based on information extracted by PM. Afterward, the case is sorted using high rating similarity through case-based reasoning, and the degree of defects is predicted by aggregating the values from high rated cases. The process is shown in Figure 8. Kim (2016) 
suggested an exterior wall selection method by deriving a coefficient for the degradation of material performance over time and analyzing the material values, taking into consideration the degradation.

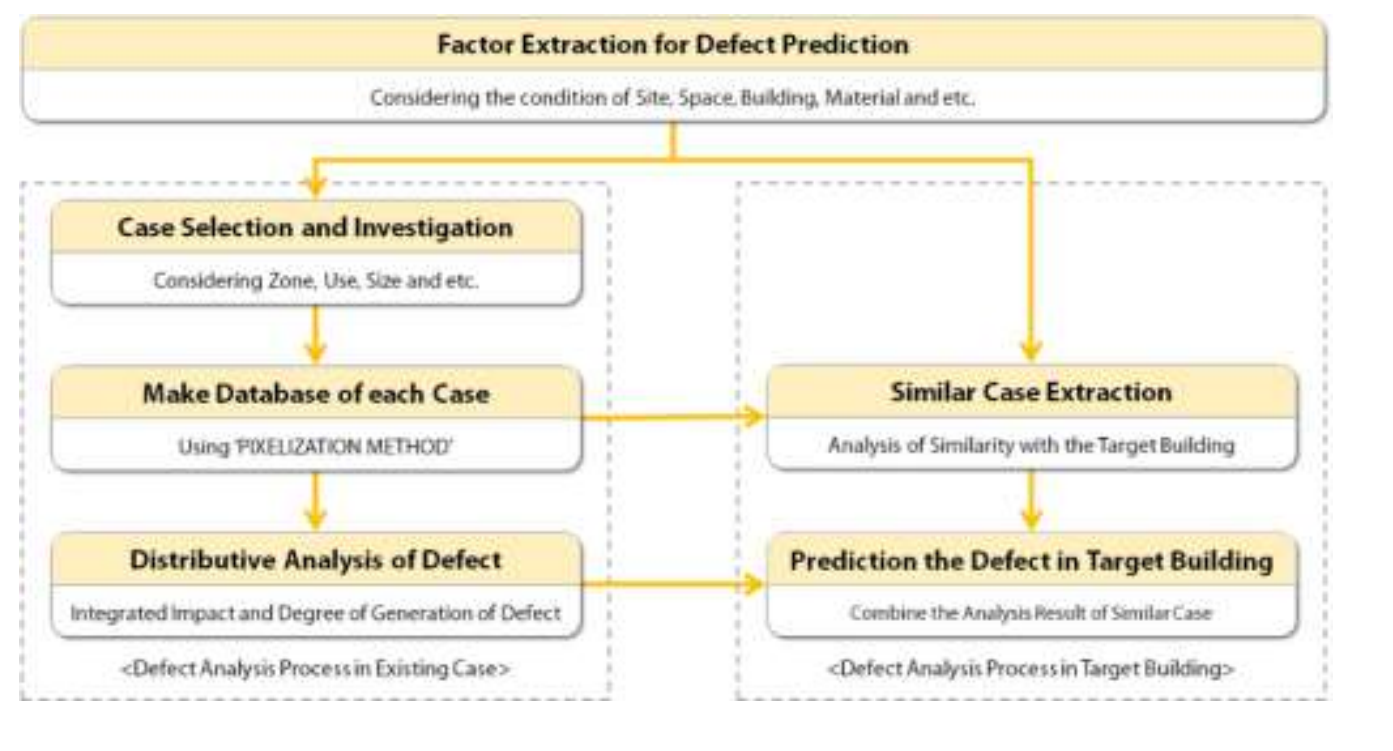

Figure 8. Prediction Process for the Degree of Defect through Case-based Reasoning

Based on this process, a foundation can be formed to choose a response strategy such as modification of finishing materials, arrangement of elevation components and proceeding with prior knowledge andacceptance of the degree of defects that will occur in the building.

\subsection{Summary}

Data obtained from PM is neant to quantify information about defects and façade elements. After a review of practical utilization, the possibilities for utilization such as relation ship analysis bely)een defects and façade elements as well as predictions about the amount of defects were confirmed.

Compared to previous studies, the pace of data processing has increased, and the necessity of collecting various types of data is magnified due to advanced analysis techniques. From reviewing PM in this study, we concluded that it can be approached and utilized in various ways.

\section{Conclusions}

This study introduces the "Pixelization Method" (PM) for creating a database to prevent common defects that occur on building facades. PM is an efficient method for collecting data by inputting simplified codes based on the characteristics of elevation and the defects in existing buildings. PM can be used as the foundation for generating predictions of related elevation components and defects as well as defect occurrence regarding the properties of buildings.

The purpose of this study is to create a base for defect prevention on exterior walls. The study applied the concept of crime prevention through environmental design (CPTED). CPTED proposes a design guideline for crime prevention that involves analyzing data on crime in specific areas regarding its urban design. Defects would conceivably be prevented through practical methods determined from 
the collected data by adapting the concept of defects found in building facades. Defects are a risk, not a crisis. They can be predicted and prevented. A large amount of information on defects is needed for this purpose, and this study is expected to provide a foundation that paves the way for collecting the necessary information to prevent defects in building façades.

\section{Acknowledgement}

This research was supported by the Basic Science Research Program through the National Research Foundation of Korea (NRF) funded by the Ministry of Science, ICT and future Planning (No. 2015R1A2A2A01006826).

\section{References}

[1] A. Silva, J. de Brito, P.L. Gaspar, "Service life prediction model applied to natural stone wall claddings" (directly adhered to the substrate)", Construction and Building Materials, 25, 9, (2011), 3674-3684

[2] B. Lourenco Paulo, Luso Edurada, G. Almeida Manuela, "Defects and moisture problems in buildings from historical city centres: a case study in Portugal", Building and Environment, 41, 2,(2005), 223-234

[3] C. M. Grossi, P. Brimblecombe, Rosa M. Esbert, Francisco J. Alonso, "Color changes in architectural limestones from pollution and cleaning", Color research and application, 21, 4, (2005), 320-331

[4] C. M. Grossi, P. Brimblecombe, "Aesthetic thresholds and blackentng of stone building", Science of the Total, 349, (2005), 175-189

[5] D. Y. Kim, "Proposing a façade design process of CABS using getnetic algorithm", MS thesis, Sungkyunkwan University, Seoul, (2013)

[6] I. H. Kim, "Construction Management and Strategy for Decision Making", Seoul : Kimundang Press (2008)

[7] J. S. Lee, Y. D. Jeon, K. C. Chang, W. R. Kin, 'The 'Pixelization Method' for data Mining of 'Defect Prevention through Exterior Wall Design"'Advanced Science and Technology Letters, (2016), 124, 5359

[8] KSCA(Korea Standard Color Analysis), (2014), http:/hww.kats.go.kr

[9] K. W. Kwon, I. C. Song, "Study for cause of building stone contamination and elemental analysis of contaminant compound", Journal of Architectural Institute of Korea, 11, 7, (1995), 245-252

[10] L. Holloway, "Materials Selectron for Optimal Lnvironmental impact in Mechanical Design", Material \& Design, 19, 4, (1998), 133-143

[11] N. Neto, J. de Brito, "Valiaation of and imspection and diagnosis system for anomalies in natural stone cladding", Construction and Building, (2012), 30, 224-236

[12] R. L. Hébert, L. Beouch, O. Fichet, N Prichystal, "Cracks and strains on façade-cladding made of carbonate rock thin panels", Structural Survey, 30, 2, (2012), 130-144

[13] R. Barletta, "Ân introduction to case-based reasoning", AI EXPERT, 6, 8, (1991), $42-49$

[14] S. I. Hong, C. T. Hyun, S. B An, S. M. Jee, M. J. Son, "Selection of Primary Management Objects for Defect Prevention of Apartment Finishing Works", Journal of the Architectural Institute of Korea, 27, 7, (2011), 185-194

[15] T. Atsushi, H. Mark, W. Stefan, "A multidisciplinary approach to sustainable building material selection: A case study in a Finnish context", Building and Environment, 82, (2014), 526-535

[16] U. S. Sim, "Case Study for Building Contamination and Prevention", Seoul : Spacetime Press (2001)

[17] W. R Kim, "Value Analysis Model for Exterior Wall Finishing Materials considering Deterioration, Ph.D. Dissertation, Dongguk Univ. Seoul, (2016)

[18] Y. S. Seo, S. M. Kang, "A Study on the Characteristics and Trend of the External Finishing Material in Modem Low-rise Commercial Buildings", Journal of Korean Housing Association, 11, 3, (2013), 171-

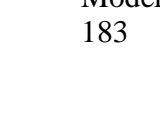

\section{Authors}

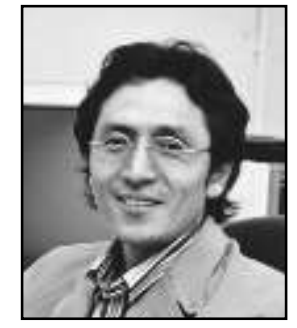

Jaeseob Lee, he is a Professor, Building Construction \& Law, Division of Architectural Engineering, Dongguk University, 30, Pildong-ro 1-gil, Jung-gu, Seoul, Rep. of Korea. js1998@dongguk.edu 


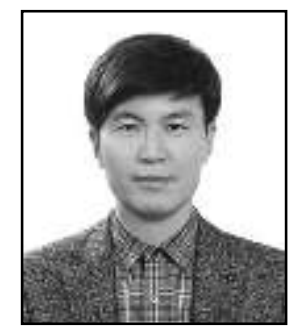

Yongdeok Jeon, he is doing Doctorate Program in division of Architectural Engineering(Construction and Construction Management), Dongguk University, 30, Pildong-ro 1-gil, Jung-gu, Seoul, Rep. of Korea. claimjeon@ naver.com

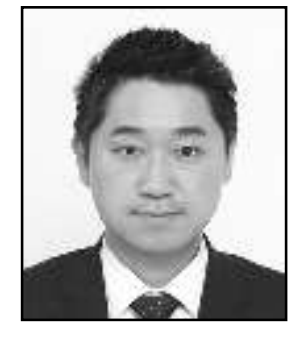

Kichang Jeong, he is a Standing Executive Director of Construction Cost Management Research Institute, 508, Baekjegobun-ro, Songpa-gu, Seoul, Rep. of Korea. therza@hanmail.net

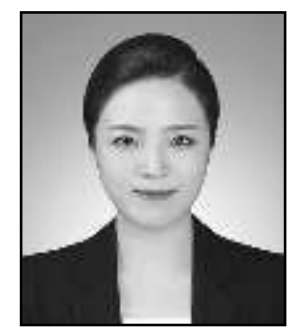

Yeonwoo Shin, she is an undergraduatê student in division of Architectural Engineering, Dongguk Unversity, 30. Pildong-ro 1gil, Jung-gu, Seoul, Rep. of Korea yeonwoo124@ hotmail.com

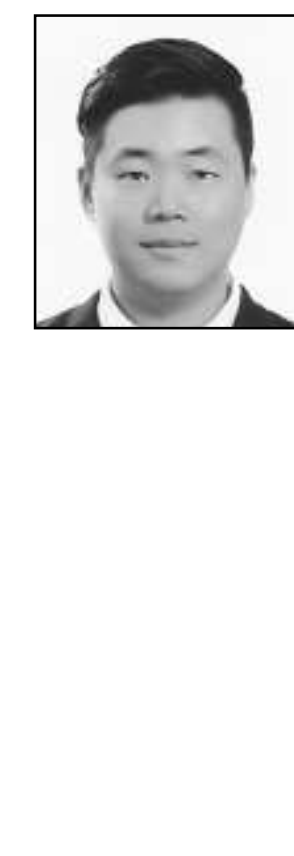

Wooram Kim, be is a Research Professor, Construction \& Material Diyision of Architectural Engineering, Dongguk University, 30, Pildonge 1-gil, Jung-gu, Seoul, Rep. of Korea. seraphs4u@naver.com 
International Journal of Smart Home

Vol.10, No.12 (2016)

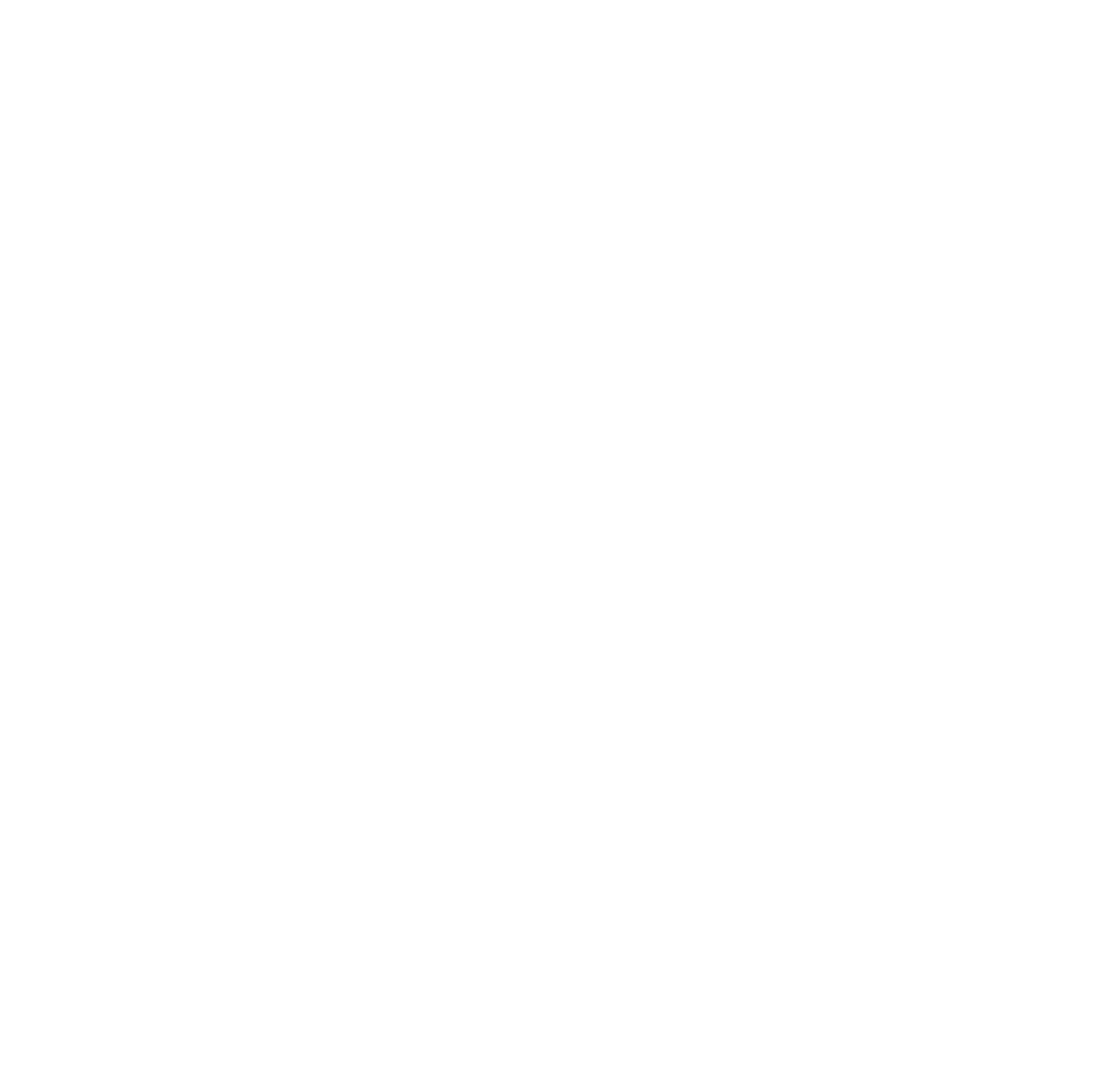

